Article

\title{
Antioxidant, Anti-inflammatory Activities and Polyphenol Profile of Rhamnus prinoides
}

\author{
Gui-Lin Chen ${ }^{1,2,3,+}$, Fredrick Munyao Mutie ${ }^{1,2,4,+} \mathbb{D}$, Yong-Bing Xu ${ }^{1,2,3,4}$, Flora Didii Saleri ${ }^{1,2,4}$, \\ Guang-Wan $\mathrm{Hu}{ }^{1,2,3}$ and Ming-Quan Guo ${ }^{1,2,3, * \mathbb{D}}$ \\ 1 CAS Key Laboratory of Plant Germplasm Enhancement and Specialty Agriculture, Wuhan Botanical Garden, \\ Chinese Academy of Sciences, Wuhan 430074, China; glchen@wbgcas.cn (G.-L.C.); \\ fredrick.munyao02@gmail.com (F.M.M.); xuyongbing17@mails.ucas.ac.cn (Y.-B.X.); \\ didiiflora@gmail.com (F.D.S.); guangwanhu@wbgcas.cn (G.-W.H.) \\ 2 Sino-Africa Joint Research Center, Chinese Academy of Sciences, Wuhan 430074, China \\ 3 Innovation Academy for Drug Discovery and Development, Chinese Academy of Sciences, Shanghai 201203, \\ China \\ 4 Graduate University of Chinese Academy of Sciences, Beijing 100049, China \\ * Correspondence: guomq@wbgcas.cn; Tel.: +86-027-87700850 \\ + These authors contributed equally to this work.
}

Received: 27 February 2020; Accepted: 22 March 2020; Published: 26 March 2020

check for updates

\begin{abstract}
Rhamnus prinoides L'Herit (R. prinoides) has long been widely consumed as folk medicine in Kenya and other Africa countries. Previous studies indicated that polyphenols were abundant in genus Rhamnus and exhibited outstanding antioxidant and anti-inflammatory activities. However, there are very few studies on such pharmacological activities and the polyphenol profile of this plant up to now. In the present study, the antioxidant activities of the crude $R$. prinoides extracts (CRE) and the semi-purified $R$. prinoides extracts (SPRE) of polyphenol enriched fractions were evaluated to show the strong radical scavenging effects against 1,1-diphenyl-2- picrylhydrazyl radical 2,2-diphenyl-1-(2,4,6-trinitrophenyl) hydrazyl (DPPH) $(0.510 \pm 0.046$ and $0.204 \pm 0.005, \mathrm{mg} / \mathrm{mL})$, and 2,2' -azinobis-(3-ethylbenzthiazoline-6-sulfonic acid) (ABTS) (0.596 \pm 0.005 and $0.096 \pm 0.004$, $\mathrm{mg} / \mathrm{mL}$ ), respectively. Later, the SPRE with higher contents of polyphenols and flavonoids displayed obvious anti-inflammatory activities through reducing the NO production at the dosage of $11.11-100 \mu \mathrm{g} / \mathrm{mL}$, and the COX-2 inhibitory activity with an $\mathrm{IC}_{50}$ value at $20.61 \pm 0.13 \mu \mathrm{g} / \mathrm{mL}$. Meanwhile, the HPLC-UV/ESI-MS/MS analysis of polyphenol profile of $R$. prinoides revealed that flavonoids and their glycosides were the major ingredients, and potentially responsible for its strong antioxidant and anti-inflammatory activities. For the first time, the present study comprehensively demonstrated the chemical profile of $R$. prinoides, as well as noteworthy antioxidant and anti-inflammatory activities, which confirmed that $R$. prinoides is a good natural source of polyphenols and flavonoids, and provided valuable information on this medicinal plant as folk medicine and with good potential for future healthcare practice.
\end{abstract}

Keywords: Rhamnus prinoides; polyphenols; antioxidant; anti-inflammatory; chemical profile

\section{Introduction}

Rhamnus prinoides L'Herit (R. prinoides), belonging to family Rhamnaceae, and also commonly known as dogwood or Gesho in Amharic, is widely distributed in many countries of eastern, central, and southern Africa [1]. This plant has numerous valuable uses in local communities: the fruits are edible as a food source; the wood is hard and used as timber; and the stems and branches are usually made into ornaments, shades, fence edges, etc. [2]. Nowadays, as an important hopping agent in 
the beer industry, the stems and leaves of this plant are the all-important ingredients to provide the characteristic bitter flavor, and to inhibit the growth of some species of bacteria, when preparing the fermented commercial beverages, Tella and Tedj, in Ethiopia and Cameroon, and it is predicted that these prevalent beverages are consumed by over 5 million people daily in Ethiopia [1,3,4].

Although exotic to Kenya, R. prinoides occurs commonly in Rift-valley and Central provinces and has been used as a traditional folk herb medicine for centuries. The root decoction can be taken orally or mixed with milk as a blood purifier and gargle, and also for the treatment of the dyspepsia, flu/cold, brucellosis, rheumatism, pneumonia, stomach-ache, back pain, gonorrhea, and malnutrition $[5,6]$. The leaves can be made into liniment to alleviate joint sprains, and its decoction can be used for chest pain, stomach complications, fever, common cold, diarrhea, malaria, and ringworm infections [1,7]. The combination of leaves/stems can be applied for the therapy of tonsil in central Kenya [8]. Currently, an in vitro anti-plasmodium study on many plants used in Kisii, Kenya, displayed that aqueous extracts from the root bark of $R$. prinoides exerted distinct antimalarial effects against both chloroquine (CQ)-sensitive and Plasmodium falciparum with an $\mathrm{IC}_{50}$ values less than $30 \mu \mathrm{g} / \mathrm{mL}$ [9]. In another effort on in vivo antimalarial activities in Kenya, the hot water extracts of $R$. prinoides root barks exhibited high chemo suppression of $51 \%$ at the dosage of $500 \mathrm{mg} / \mathrm{kg}$ in mice on the CQ-resistant Plasmodium berghei NK65. Meanwhile, its leaf extracts showed striking parasitemia suppression and prolonged the survival of mice in a case of more than 2 weeks [10]. Besides, the sonicated aqueous extracts of $R$. prinoides root exhibited distinct acetylcholinesterase (ACE) inhibition with an $\mathrm{IC}_{50}$ value at $0.201 \mathrm{mg} / \mathrm{mL}$, and showed potential utility in the treatment of Alzheimer's disease [11].

Except for the essential and non-essential metals, volatile oils, and saponins with lower content, present phytochemical studies indicated that $R$. prinoides mainly contains varieties of phenolic compounds, including flavonoids, anthraquinones, naphthols, and their glycosides [1,12-15]. For example, the geshoidin, a naphthalene glycoside ( $\beta$-sorigenin-8-O- $\beta$-D-glucoside), is one of the most important compounds in this plant, and partially responsible for the characteristic bitterness in the popular beverages of Tella. In addition, the discovery of this compound is of highlighted significance in studying the phytochemicals of this plant [16]. Polyphenols are the main antioxidant components in plants. On the one hand, polyphenols possess strong total reducing power, 1,1-diphenyl-2-picrylhydrazyl radical 2,2-diphenyl-1-(2,4,6-trinitrophenyl) hydrazyl / 2,2'-azinobis- (3-ethylbenzthiazoline-6-sulfonic acid) $\left(\mathrm{DPPH} / \mathrm{ABTS}^{+}\right)$free radicals, and nitrite scavenging activities [17]; on the other hand, these compounds could closely be involved in many physiological processes, including but not limited to inflammation, antibiosis, hyperlipidemia, hyperglycemia, and cancer [18-20]; for example, polyphenols could inhibit the bioactivities of the vascular endothelial growth factor (VEGF) so as to suppress vascular regeneration [21]. As a matter of fact, however, there are still few reports about the potentials of polyphenols in $R$. prinoides in Kenya for antioxidants and their related activities. Today, more than $60 \%$ of the population in South Africa consumes traditional herbal medicines, and still up to 1.5 billion people worldwide consult the medicinal plants as their primary health care, especially in rural areas of developing countries [22]. Hence, with the growing interests in traditional herb medicines worldwide, the present study aims to comprehensively explore the antioxidant and anti-inflammatory characteristics and the polyphenol profile of the traditional ethno-medicine, $R$. prinoides in Kenya, and then further provide practical guidance for quality control $(\mathrm{QC})$ and its daily and clinical usages as valuable research resource for the development of new natural pharmaceuticals.

\section{Results and Discussion}

\subsection{Enrichment and Phytochemical Contents}

Our early work suggested that $60 \%$ ethanol solution was applicable for the extraction of polyphenols in Rhamnus davurica [23]. As shown in Table 1, the total phenolic content (TPC) and total flavonoids content (TFC) of the crude R. prinoides extracts (CRE) were $228.21 \pm 13.34$ gallic acid 
equivalents (GAE)/g and $352.25 \pm 10.95 \mathrm{RE} / \mathrm{g}$, which were eight times higher than that of dry R. prinoides powders at $26.86 \pm 1.57 \mathrm{GAE} / \mathrm{g}$ and $41.46 \pm 4.80 \mathrm{RE} / \mathrm{g}$, respectively. Polyamide is a kind of polymer containing amide bonds (-CONH-), which can tightly absorb and bind with the compounds with hydroxyl phenols, acids, quinones, and nitro groups by the hydrogen bonds. Therefore, polyamide resin is particularly suitable for the purification and separation of the phenolic components from the complex natural products, including flavonoids, phenolic acids, quinones, carbonyl, and carboxyl compounds [24]. After purification with the polyamide resin in the present study, the TPC and TFC in semi-purified $R$. prinoides extracts (SPRE) went up to $553.67 \pm 7.06 \mathrm{GAE} / \mathrm{g}$ and $958.21 \pm 21.18 \mathrm{RE} / \mathrm{g}$, showing an almost three times higher than that of in CRE. Based on the yields of CRE (11.72\%) and SPRE (1.36\%) to the R. prinoides powders, the higher TPC and TFC values in SPRE in this study also demonstrated the effective application of polyamide resin for the enrichment of the polyphenols. In this regard, the CRE (352.25 $\pm 10.95 \mathrm{mg} \mathrm{RE} / \mathrm{g}$ extract) and SPRE (958.21 $\pm 21.18 \mathrm{mg} \mathrm{RE} / \mathrm{g}$ extract) in this study obtained from $R$. prinoides in Kenya communities presented higher TFC values than that of the methanol extract (51.17 mg quercetin equivalent (QE)/g extract), aqueous extract (24.09 mg QE/g extract) and traditional boiling aqueous extract (12.03 $\mathrm{mg}$ QE/g extract) of Rhamnus alaternus bark from Algeria [25], and ethyl acetate (EA) extract (108.03 $\pm 3.09 \mathrm{mg}$ catechin equivalent (CE)/g extract) of Rhamnus lycioides leaves from Algeria [26]. The distinct diversities of TFC values in the aforementioned extracts might be caused by the differences of extraction solvent polarities and purification processes.

Table 1. Total phenolic content (TPC) and total flavonoids content (TFC) of the extracts and fractions of R. prinoides.

\begin{tabular}{ccc}
\hline & TPC $(\mathbf{m g ~ G A E} / \mathbf{g})$ & TFC $(\mathbf{m g ~ R E} / \mathbf{g})$ \\
\hline \multirow{2}{*}{ CRE } & $26.86 \pm 1.57^{\mathrm{a}}$ & $41.46 \pm 4.80^{\mathrm{a}}$ \\
& $228.21 \pm 13.34^{\mathrm{b}}$ & $352.25 \pm 10.95^{\mathrm{b}}$ \\
\cline { 2 - 3 } SPRE & $553.67 \pm 7.06^{\mathrm{c}}$ & $958.21 \pm 21.18^{\mathrm{c}}$
\end{tabular}

Results are expressed as the Mean $\pm \mathrm{SD}(\mathrm{n}=3)$. CRE, crude $R$. prinoides extracts; SPRE, semipurified $R$. prinoides extracts; TPC, total phenolic content; TFC, total flavonoids content; GAE, gallic acid equivalents; RE, rutin equivalents. a Based on R. prinoides powders. ${ }^{\mathrm{b}}$ Based on CRE. ${ }^{\mathrm{c}}$ Based on SPRE.

\subsection{Evaluation of Antioxidant Activities}

The antioxidant activities of the CRE and SPRE were evaluated by the most frequently-used DPPH and ABTS radical scavenging tests, and all the results were expressed as $\mathrm{IC}_{50}$ and Trolox equivalents (TEs) and shown in Table 2. For the DPPH assays, the SPRE at $\mathrm{IC}_{50}$ of $0.204 \pm 0.005 \mathrm{mg} / \mathrm{mL}$ exerted significantly higher scavenging activity than CRE of $0.510 \pm 0.046 \mathrm{mg} / \mathrm{mL}(p<0.01)$, together with the similar trend the $2361.3 \pm 57.9 \mu \mathrm{M} \mathrm{TE} / \mathrm{g}$ and $945.5 \pm 85.2 \mu \mathrm{M} \mathrm{TE} / \mathrm{g}(p<0.01)$. As for the ABTS assays, the SPRE also exhibited higher ABTS free scavenging activities compared with the CRE in regard to the $\mathrm{IC}_{50}$ values $(0.096 \pm 0.004$ vs. $0.596 \pm 0.005, \mathrm{mg} / \mathrm{mL})$ and TEs $(1697.9 \pm 70.7$ vs. $273.5 \pm 2.29, \mu \mathrm{M} \mathrm{TE} / \mathrm{g})$ $(p<0.01)$. Interestingly, the SPRE displayed higher DPPH scavenging activity of $\mathrm{IC}_{50}$ at $0.204 \pm 0.005$ $\mathrm{mg} / \mathrm{mL}$ and TE at $2361.3 \pm 57.9 \mu \mathrm{M} \mathrm{TE} / \mathrm{g}$ than the positive control butylated hydroxytoluene (BHT) of $\mathrm{IC}_{50}$ at $0.286 \pm 0.010 \mathrm{mg} / \mathrm{mL}$ and $\mathrm{TE}$ at $1684.3 \pm 46.3 \mu \mathrm{M} \mathrm{TE} / \mathrm{g}$, which simultaneously confirmed the antioxidant potential of $R$. prinoides.

Similar studies revealed that the bark extracts of four Rhamnus species from Croatia communities, namely Rhamnus alaternus, Rhamnus fallax, Rhamnus intermedia, and Rhamnus pumila, displayed relatively lower DPPH values of 78.7 $\pm 3.16,22.3 \pm 0.54,72.2 \pm 4.00$, and $53.1 \pm 1.57 \mu \mathrm{g} / \mathrm{mL}$ [27], respectively, and also the bark extracts of Rhamnus catharticus and Rhamnus orbiculatus from Dedin and Mt. Sniježnica with the efficient concentration $\left(\mathrm{EC}_{50}\right)$ values of $64 \pm 5$ and $89 \pm 2 \mu \mathrm{g} / \mathrm{mL}$ [28], respectively. Hence, the obtained antioxidant activities for the above extracts might be a result of the high TPC and TFC levels quantified in the extracts. As a matter of fact, phenolic compounds are commonly closely correlated with antioxidant activities, which might be due to their hydrogen- donating properties as free radical 
scavengers. Particularly, lots of well-known flavonoids, such as quercetin, kaempferol, isorhamnetin, rhamnetin, and their glycosides identified in the present study, might be attributed to those results [26].

Table 2. $\mathrm{IC}_{50}$ Values of the crude $R$. prinoides extracts (CRE) and the semi-purified $R$. prinoides extracts (SPRE) of $R$. prinoides on the 2,2-diphenyl-1-picrylhydrazyl (DPPH) and 2,2'-Azinobis(3-ethylbenzthiazoline-6-sulfonic acid) (ABTS) free radicals.

\begin{tabular}{ccccc}
\hline \multirow{2}{*}{ Sample } & \multicolumn{2}{c}{ DPPH } & \multicolumn{2}{c}{ ABTS } \\
\cline { 2 - 5 } & IC $_{\mathbf{5 0}}(\mathbf{m g} / \mathbf{m L})$ & $\mu \mathbf{M ~ T E} / \mathbf{g}$ & IC $_{\mathbf{5 0}}(\mathbf{m g} / \mathbf{m L})$ & $\mu \mathbf{M ~ T E} / \mathbf{g}$ \\
\hline CRE & $0.510 \pm 0.046$ & $945.5 \pm 85.2$ & $0.596 \pm 0.005$ & $273.5 \pm 2.29$ \\
SPRE & $0.204 \pm 0.005^{* *}$ & $2361.3 \pm 57.9$ & $0.096 \pm 0.004 * *$ & $1697.9 \pm 70.7$ \\
BHT & $0.286 \pm 0.010$ & $1684.3 \pm 46.3$ & $0.059 \pm 0.003$ & $2762.7 \pm 71.2$ \\
Trolox & $0.121 \pm 0.005$ & ND & $0.041 \pm 0.002$ & ND \\
\hline
\end{tabular}

Results are expressed as the Mean \pm SD $(n=3)$. DPPH: 2,2-diphenyl-1-picrylhydrazyl; ABTS: 2,2'-Azinobis-(3-ethylbenzthiazoline-6-sulfonic acid); BHT, butylated hydroxytoluene; CRE, crude R. prinoides extracts; SPRE, semipurified $R$. prinoides extracts; half maximal inhibitory concentration $\left(\mathrm{IC}_{50}\right)$ value represents the concentration that leads to $50 \%$ decrease in the scavenging of DPPH or ABTS radical; $\mu \mathrm{M} \mathrm{TE} / \mathrm{g}, \mu \mathrm{M}$ Trolox equivalents per gram of sample; ND, Not detected. ${ }^{* *} p<0.01$, compared with CRE.

As the active part, the $\mathrm{H}$ atoms in the hydroxyl groups of polyphenols can combine with the free radicals to form the polyphenol-radicals, and then react with other radicals, thus terminating the radical chain reaction [29]. In this current assay, it was assumed that the DPPH-and $\mathrm{ABTS}^{+}$free radicals in the solution turned into the non-radicals of the DPPH-H and ABTS, once encountering the $\mathrm{H}$ atom donors of hydroxyl groups of polyphenols in $\mathrm{R}$. prinoides. That is to say, the active $\mathrm{H}$ atom donors, polyphenols, in $R$. prinoides possess strong antioxidant activity by capturing the DPPH and $\mathrm{ABTS}^{+}$free radicals. To this end, the SPRE was thus applied logically into the following assays.

\subsection{Evaluation of Anti-inflammatory Activities}

$\mathrm{NO}$ is an important inflammatory mediator secreted by activated macrophages. When produced in large quantities, $\mathrm{NO}$ will combine with $\mathrm{O}_{2}{ }^{-}$to form peroxynitrite anion, which is an important factor leading to cell damage, energy depletion, and cell death, as well as an important link for NO to produce pathological damages [30]. COX-2 is known as a key rate-limiting enzyme that catalyzes the biosynthesis of the prostaglandins (PGs) from the precursor compound of the arachidonic acid, which induces the inflammatory cells to release chemokines and promote the movement of the inflammatory cells, thus facilitating the occurrence and metastasis of the inflammation [31]. Considering that inhibition of COX-2 activity and NO production could reduce damages to normal cells in the process of inflammation, thus significantly alleviating the typical inflammatory symptoms, they have become two of the major targets for the treatment of inflammatory diseases. Therefore, drugs that could inhibit COX-2 activity and NO production have potential anti-inflammatory activity.

According to Figure 1a, compared with the negative group (NC) group, the NO production was significantly decelerated when the lipopolysaccharide (LPS)-stimulated RAW264.7 macrophage cells were incubated with the SPRE of $R$. prinoides at the concentrations of $11.11-100 \mu \mathrm{g} / \mathrm{mL}$ in a dose-dependent manner. Meanwhile, the SPRE in Figure $1 b$ also exhibited an obvious inhibitory effect against COX-2 with an $\mathrm{IC}_{50}$ value of $20.61 \pm 0.13 \mu \mathrm{g} / \mathrm{mL}$, compared with the positive control aspirin at an $\mathrm{IC}_{50}$ value of $6.33 \pm 0.05 \mu \mathrm{g} / \mathrm{mL}$. In previous studies, the $R$. davurica leaf extract demonstrated remarkable anti-allergic activity by getting involved in the Fyn/Syk pathway in the antigen-stimulated mast cells [32]; quercetin from Rhamnus nakaharai and frangulin B from Rhamnus formosana displayed strong inhibition against the formation of TNF- $\alpha$ in the LPS- stimulated RAW 264.7 macrophage cells with $\mathrm{IC}_{50}$ values of $49.7 \pm 6.1 \mu \mathrm{M}$ and $24.2 \pm 12.8 \mu \mathrm{M}$, respectively. Meanwhile, flavonoids of quercetin, quercetin 3-O-methyl ether, kaempferol from R. nakaharai, and frangulin B from R. formosana also displayed strong inhibition against the formation of TNF- $\alpha$ in the LPS/IFN $\gamma$-stimulated N9 cells with $\mathrm{IC}_{50}$ values of $85.6 \pm 2.2 \mu \mathrm{M}, 43.3 \pm 10.1 \mu \mathrm{M}, 11.0 \pm 4.6 \mu \mathrm{M}$, and $42.6 \pm 2.8 \mu \mathrm{M}$, respectively, 
compared with the positive control of dexamethasone at an $\mathrm{IC}_{50}$ value of $82.0 \pm 3.8 \mu \mathrm{M}$ [33]. In addition, 11 compounds were further screened out to be the potent COX-2 inhibitors from the bark extract of $R$. davurica with the UF-HPLC-MS hyphenated technique, in which vitexin, apigenin, and kaempferol exerted outstanding COX-2 inhibitory effect with $\mathrm{IC}_{50}$ values of $55.94 \pm 2.59,10.14 \pm 0.45$ and $9.27 \pm 0.43 \mu \mathrm{g} / \mathrm{mL}$, respectively [34]. However, there is no such report about the anti-inflammatory applications in floks of R. prinoides in Kenya until now. Evidences from the HPLC-MS analysis in Figure 2 and Table 3 revealed that the above-mentioned flavonoids and their glycosides were also contained in the R. prinoides extracts from Kenya communities. For the first time, hence, the present results proved the noteworthy anti-inflammatory effects of $R$. prinoides by inhibiting the COX-2 activity and NO production in RAW264.7 cells.
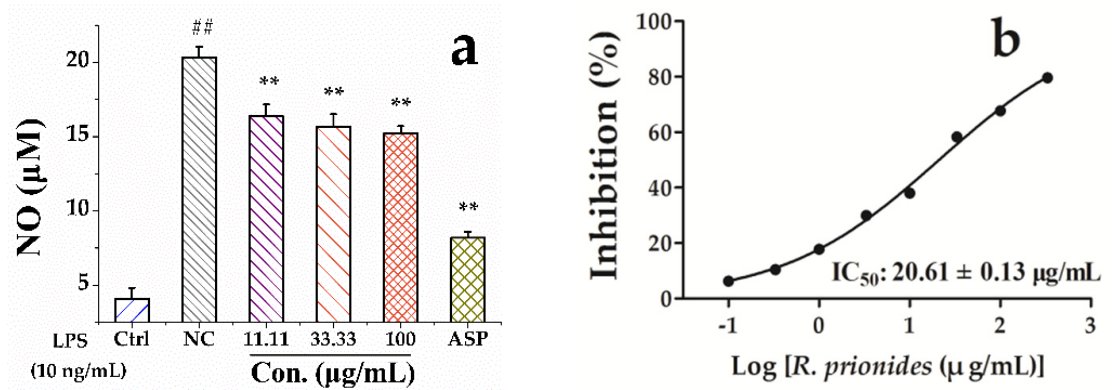

Figure 1. Anti-inflammatory activities of the semi-purified R. prinoides extracts (SPRE) of $R$. prinoides on NO production (a) and COX-2 inhibition (b). Results are expressed as the Mean \pm SD $(n=3)$. Ctrl, normal control group; NC, negative group; ASP, aspirin; LPS, lipopolysaccharide; ${ }^{* *} p<0.01$, compared with the NC group; ${ }^{\# \#} p<0.01$, compared with the Ctrl group.

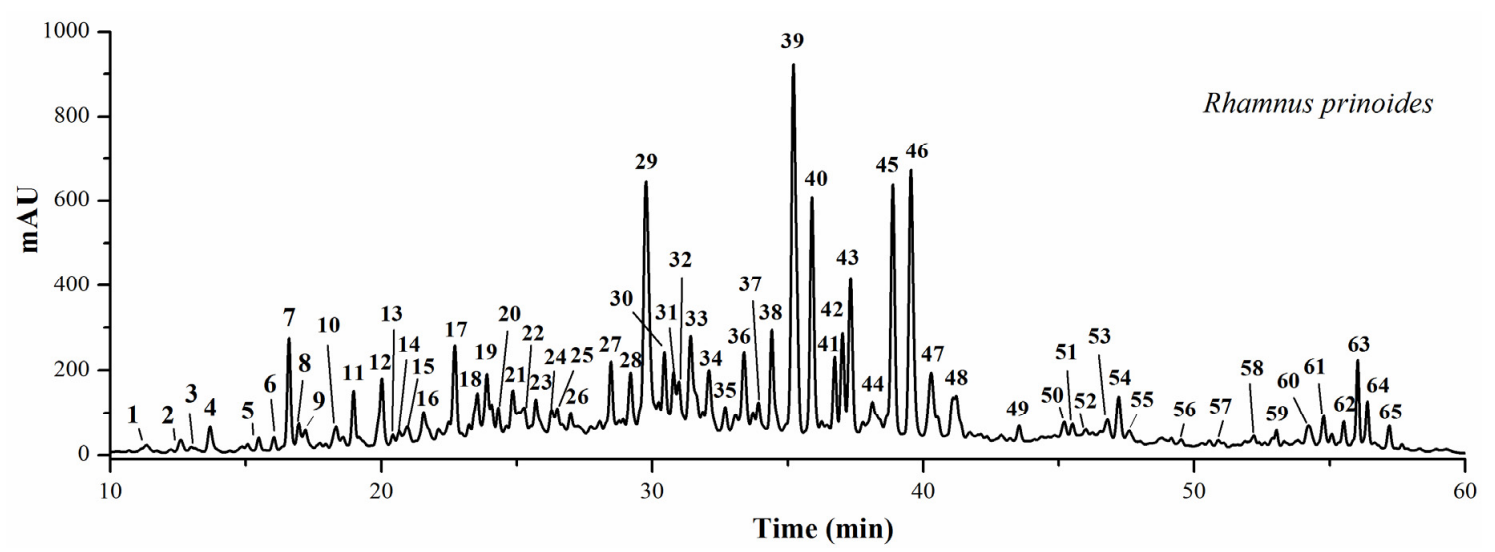

Figure 2. The HPLC-UV chromatogram profile of SPRE of $R$. prinoides (Kenya) at $360 \mathrm{~nm}$. The peak numbers in the figure correlate to those in Table 3 below.

Table 3. The HPLC-ESI-MS/MS data of the detected polyphenol profile of SPRE of R. prinoides (Kenya).

\begin{tabular}{|c|c|c|c|c|c|}
\hline Peak No. & Rt (min) & $\begin{array}{c}{[\mathrm{M}-\mathrm{H}]^{-}} \\
(\mathrm{m} / \mathrm{z})\end{array}$ & MS/MS ions & Tentative Identification & AUC (\%) \\
\hline 1 & 11.33 & 341 & $341,221,179,131,119$ & Caffeic acid 4-O-hexoside ${ }^{a}$ & 0.31 \\
\hline 3 & 12.98 & 447 & $447,285,229,207,165,137$ & Kaempferol 3-O-glucoside ${ }^{a}$ & 0.18 \\
\hline 4 & 13.68 & 305 & $305,221,179,165,125$ & Gallocatechin ${ }^{a}$ & 0.68 \\
\hline 5 & 15.48 & 577 & $577,289,245,161,125$ & Proanthocyanidin B3 ${ }^{\mathrm{a}}$ & 0.31 \\
\hline 8 & 16.95 & 483 & $483,356,353,337,239,195,127$ & $\begin{array}{l}\text { Quercetin 3-O-methyl ether } \\
\text { peracetate }^{\mathrm{a}}\end{array}$ & 0.48 \\
\hline 9 & 17.20 & 303 & $303,285,241,217,151,125$ & Taxifolin $^{\mathrm{b}}$ & 0.42 \\
\hline 10 & 18.33 & 597 & $597,465,422,353,241,209$ & Unknown & 0.61 \\
\hline
\end{tabular}


Table 3. Cont.

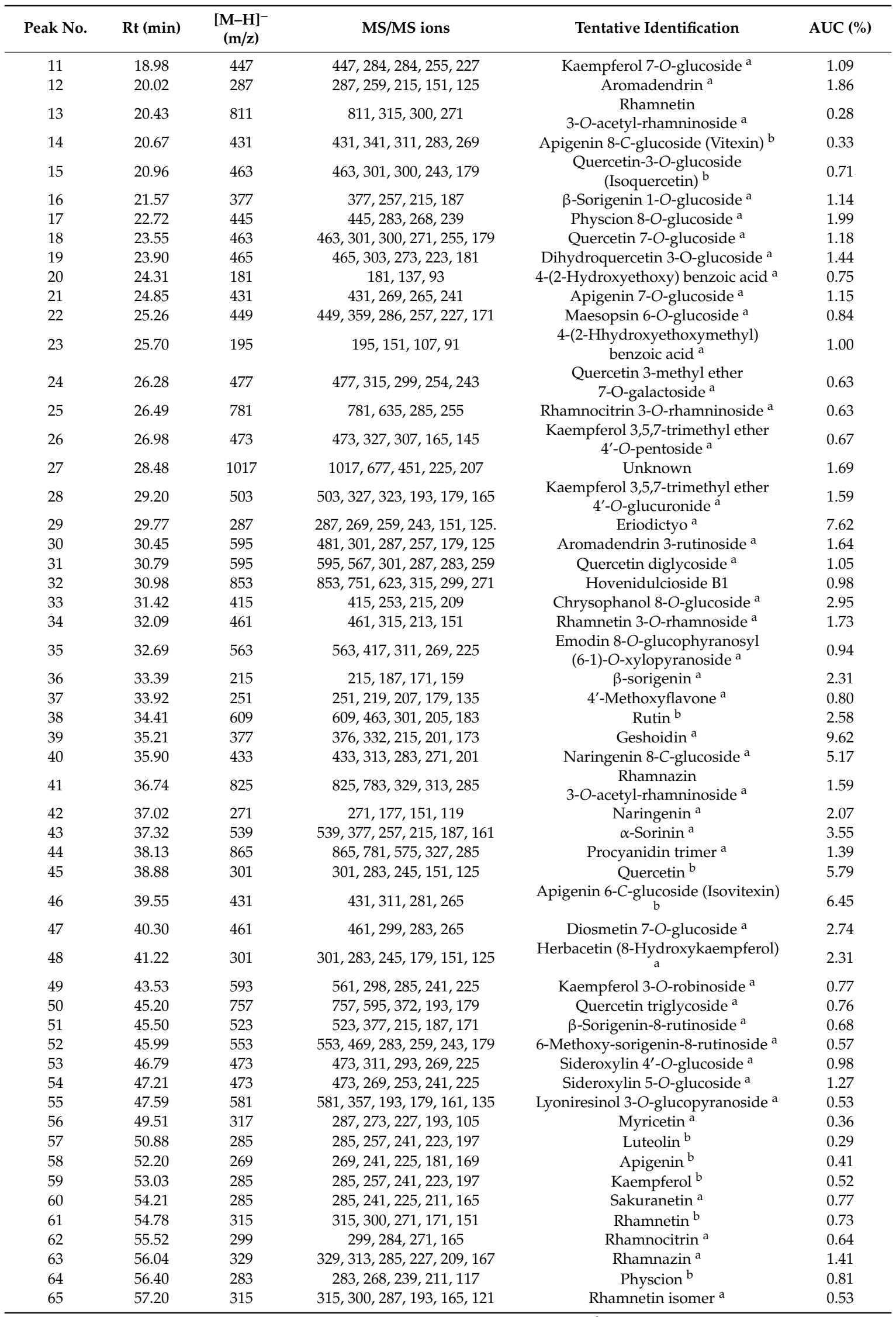

${ }^{\mathrm{a}}$ Identification and characterization by comparison with chemical standards; ${ }^{\mathrm{b}}$ Identification and characterization by comparison with the MS fragments reported in previous studies. Rt, retention time; AUC, area under the curve. 


\subsection{HPLC-UV/ESI-MS/MS Analysis}

A chemical fingerprint profile can comprehensively reflect the types and quantities of chemical components contained in medicinal plants and their products, and then describe and evaluate their quality as a whole. Therefore, it can be used to analyze the authenticity, goodness, and stability of the quality of medicinal plants and their products [23]. By combining the high separation performance of HPLC to complex samples, with high selectivity, sensitivity, and the ability to provide molecular weight and structure information of MS, the hyphenated HPLC-MS is very suitable for the comprehensive evaluation of the QC of medicinal plants [35,36]. R. prinoides has been widely used in Kenyan local communities to treat a variety of diseases. However, studies on the chemical compositions of this plant and its products remain rare, and the lack of research in this field cannot guarantee the clinical efficacy of this plant and its products. Therefore, current studies are urgently needed to analyze the chemical constituents of this medicinal plant comprehensively.

In present study, the HPLC-UV chromatogram profile of R. prinoides (Kenya) was implemented by using the HPLC-UV/ESI-MS/MS. As shown in Figure 2 above, 65 peaks were detected in SPRE. Further structural identification and characterization of those compounds in Table 3 were carried out strictly by comparison with the chemical standards or the MS fragments reported in previous studies $[12-15,23,37,38]$. As a result, several types of polyphenols, including flavonoids and their glycosides (peaks 3-9, 11-15, 18, 19, 21, 22, 24-26, 28-31, 34, 37, 38, 40-42, 44-50, 53, 54, 56-63, 65), phenols and their glycosides (peaks 1, 2, 20, 23), naphthols and their glycosides (peaks 16, 36, 39, $43,51,52$ ), anthraquinones and their glycosides (peaks 17, 33, 35, 64), phenylpropanoid glycoside (peak 55), and saponin (peak 32), are revealed majorly in R. prinoides. On this basis, further studies on spectrum-effect should also be carried out to truly correlate its QC with its clinical efficacy, and help to clarify the mechanisms of action. For the relative quantitative analysis of chemicals in SPRE, the aforementioned flavonoids, phenols, naphthols, anthraquinones, phenylpropanoid, saponin, and their glycosides take up $69.54 \%, 2.39 \%, 17.87 \%, 6.39 \%, 0.53 \%, 0.98 \%$, respectively. Most interesting, geshoidin, a naphthalenic glucoside, holds the highest content, which might be the reason that it acts as the basic bittering ingredient for the popular beverages of Tella and Tedj in Ethiopia and Cameroon [3]. Besides, geshoidin also exhibited outstanding superoxide anion $\left(\mathrm{O}_{2}{ }^{\bullet-}\right)$ scavenging activity in vitro with an $\mathrm{IC}_{50}$ value at $1.9 \mathrm{mM}$, compared with the ascorbic acid $(\mathrm{Vc})$ at $1.7 \mathrm{mM}$ [16].

Therefore, for the polyphenol profile of $R$. prinoides, in this regard, both the flavonoids profiling of the main components and the highest ingredient of geshoidin (iconic marker) strongly provide the scientific basis for the quality assurance and functional components of this medicinal and edible plant. Coincidentally, our earlier study also indicated that antioxidant activities correlated closely with the higher content of flavonoids in R. davurica [23]. In other words, the higher TFC values in SPRE further demonstrated the potent stronger antioxidant and anti-inflammatory activities of $R$. prinoides in the present study.

\section{Materials and Methods}

\subsection{Chemicals and Reagents}

The chemical standards of rutin, gallic acid, penicillin, streptomycin, aspirin (ASP), and lipopolysaccharide (LPS) were bought from Aladdin Industrial Corporation (Shanghai, China). Butylated hydroxytoluene (BHT), 6-hydroxy-2,5,7,8-tetramethyl-chroman-2-carboxylic acid (Trolox), 1,1-diphenyl-2-picrylhydrazyl radical 2,2-diphenyl-1-(2,4,6-trinitrophenyl) hydrazyl (DPPH), 2,2'azinobis-(3-ethylbenzthiazoline-6-sulfonic acid) (ABTS) were provided by Sigma-Aldrich Corp. (St. Louis, USA). MTT (3-(4,5-dimethyl-2-thiazolyl)-2,5-diphenyl-2-H-tetrazolium bromide), FBS (fetal bovine serum), and DMEM (Dulbecco's Modified Eagle Medium) were purchased from Gibco (Life Technologies, USA). Ultra-pure water was prepared with the EPED system (Nanjing Yeap Esselte Technology Development Co., Nanjing, China). All the other analytical grade chemicals and solvents were purchased from Shanghai Chemical Reagent Corp. (Shanghai, China). 


\subsection{Plant Material and Sample Preparation}

The fresh stems and stem barks of $R$. prinoides $(3.0 \mathrm{~kg})$ were collected randomly from a $10,000 \mathrm{~m}^{2}$ area of Mount Kenya (Kenya) in July of 2018. Afterward, the specimens of those plant materials were kindly authenticated by Professor Guangwan $\mathrm{Hu}$, a senior taxonomist from the Key Laboratory of Plant Germplasm Enhancement and Specialty Agriculture (Wuhan Botanical Garden, Chinese Academy of Sciences). A voucher specimen was stored in the herbarium of the Key Laboratory.

For the sample preparation, the air-dried plant materials were firstly ground to a powder with a high-speed disintegrator. Then, an aliquot of $100 \mathrm{~g}$ accurately weighted plant powders was extracted ultrasonically three times using 60\% ethanol at room temperature for $30 \mathrm{~min}$ to produce the crude R. prinoides extracts (CRE). Then the CRE were dispersed in water and extracted with petroleum ether (PE) and EA, successively. Finally, the EA extracts were loaded into a polyamide column, and the targeted semipurified $R$. prinoides extracts (SPRE) of the polyphenols enriched fraction was prepared by eluting with $80 \%$ ethanol solution. The yields of CRE and SPRE were referred to the percentage of the dry weight of the extracts to the dry plant samples, and calculated based on the formula below:

$$
\text { Yield }(\%)=\frac{\text { Weight of dry extract }}{\text { Weight of dry plant samples }} \times 100
$$

\subsection{Determinations of Phenolic Constituents}

\subsubsection{Determination of Total Phenolic Content (TPC)}

The total phenolic contents in the above two extracts were measured using the Folin-Ciocalteu method [39] with some modifications. In brief, $200 \mu \mathrm{L}$ of the properly diluted sample solutions or the standard gallic acid (GA) solutions were firstly mixed with an equivalent Folin-Ciocalteu reagent $(0.25 \mathrm{M})$ by vortexing. After that, $1000 \mu \mathrm{L}$ of $\mathrm{Na}_{2} \mathrm{CO}_{3}(1.0 \mathrm{M})$ and $600 \mu \mathrm{L}$ of $\mathrm{H}_{2} \mathrm{O}$ were added and mixed gently. Later, the reaction mixtures were further cultivated for $1 \mathrm{~h}$ at room temperature in the dark, and finally, the absorbed optical density (AOD) was recorded at the wavelength of $760 \mathrm{~nm}$. The GA was served as the standard, and the TPC was defined as milligram of GA equivalents per gram of the sample (mg GAE/g).

\subsubsection{Determination of Total Flavonoid Content (TFC)}

The total flavonoid content in all samples was determined with the previous colorimetric report [40] using rutin as a standard flavonoid compound. In brief, $180 \mu \mathrm{L}$ of the properly diluted extracts or rutin standard solutions were firstly mixed with $1080 \mu \mathrm{L}$ of $\mathrm{H}_{2} \mathrm{O}$ and subsequently with $60 \mu \mathrm{L}$ of $5 \%$ $\mathrm{NaNO}_{2}$ solution. After incubation for $6 \mathrm{~min}, 120 \mu \mathrm{L}$ of $10 \% \mathrm{AlCl}_{3}$ solution was then added and left to stand for $6 \mathrm{~min}$. After that, $360 \mu \mathrm{L}$ of $4 \% \mathrm{NaOH}$ solution was added, and these reaction mixtures were kept for another $15 \mathrm{~min}$ at room temperature. The AODs of these reaction mixtures were detected at the wavelength of $510 \mathrm{~nm}$, and the TFC was defined as milligram of rutin equivalents per gram of the sample (mg RE/g).

\subsection{Determinations of Antioxidant Activity}

\subsubsection{DPPH Free Radical Scavenging Activity}

The DPPH free radical scavenging assay was carried out in 96-well microliter plates according to a previously described method [41]. Briefly, $10 \mu \mathrm{L}$ of the Trolox or sample solutions at various concentrations were mixed with $190 \mu \mathrm{L}$ of the DPPH methanol solution (100 $\mu \mathrm{M}$, final concentration) in the 96- well plate. Then, the reaction mixtures were shaken gently and cultivated in the dark for $0.5 \mathrm{~h}$ at room temperature. Thereafter, the discoloration of DPPH radicals was detected through recording the AOD at the wavelength of $517 \mathrm{~nm}$ with a Tecan microplate reader (Infinite M1000, Switzerland). $\mathrm{BHT}$ was used as the positive control. The DPPH radical scavenging activity (RSA) was calculated 
as the equation: RSA $(\%)=[($ Acontrol - Asample $) /$ Acontrol $] \times 100 \%$. Each sample solution test was repeated three times, and all the results of the two flavonoid fractions were described to be micromolar Trolox equivalents (TE) per gram of the sample ( $\mu \mathrm{M} \mathrm{TE} / \mathrm{g})$.

\subsubsection{ABTS Free Radical Scavenging Activity}

The ABTS radical scavenging activity was assessed using a previous method [41]. In brief, the $\mathrm{ABTS}^{+}$stock solution was first prepared by mixing the ABTS solution $\left(7.0 \mathrm{mM}\right.$, in $\left.\mathrm{H}_{2} \mathrm{O}\right)$ and an equal volume of the potassium persulfate solution $\left(2.45 \mathrm{mM}\right.$, in $\left.\mathrm{H}_{2} \mathrm{O}\right)$ in darkness for $12-16 \mathrm{~h}$. After that, the $\mathrm{ABTS}^{+}$working solution was prepared through successively diluting the $\mathrm{ABTS}^{+}$stock solution with $80 \%$ ethanol to the AOD of $0.70 \pm 0.01$ at the wavelength of $734 \mathrm{~nm}$. The reaction mixture was composed of $10 \mu \mathrm{L}$ of the Trolox or sample solution and $190 \mu \mathrm{L}$ of the $\mathrm{ABTS}^{+}$working solution, and then cultivated in the dark for $0.5 \mathrm{~h}$. The AOD at the wavelength of $734 \mathrm{~nm}$ was obtained in triplicate. The calculation and expression of ABTS were consistent with the above mentioned DPPH radical scavenging activity.

\subsection{Determination of Anti-inflammatory Activities}

\subsubsection{Measurement of LPS-stimulated NO in Macrophage RAW 264.7 Cells}

The RAW264.7 macrophage cells were purchased from the American Type Culture Collection (ATCC). The cells were maintained at $37^{\circ} \mathrm{C}$ in DMEM medium supplemented with the $10 \%$ FBS, $1 \%$ penicillin-streptomycin with $5 \% \mathrm{CO}_{2}$ in a humidified incubator. The nitrite concentration, an indicator of the NO synthesis, was measured based on the previously described Griess reaction method [42]. Briefly, RAW 264.7 cells were transferred into the 96-well plate with a density of $5 \times 10^{4}$ cells/well and kept for $24 \mathrm{~h}$. These cells were incubated with various concentrations of the SPRE solution for $2 \mathrm{~h}$ and then followed by the incubation with $10 \mathrm{ng} / \mathrm{mL}$ of LPS for another $24 \mathrm{~h}$. Meanwhile, $10.0 \mu \mathrm{g} / \mathrm{mL}$ of aspirin was used as the positive control. After that, $100 \mu \mathrm{L}$ of the culture supernatant was cultivated with the same volume of Griess reagent for $15 \mathrm{~min}$ at room temperature, and the AOD was finally determined with a microplate reader at the wavelength of $540 \mathrm{~nm}$, according to the manufacturer's instructions.

\subsubsection{COX-2 Inhibition Assay}

Along with the aspirin used as the positive control, the in vitro COX-2 inhibitory test was implemented based on our previous method [34]. Briefly, COX-2 (1U, $20 \mu \mathrm{L})$ was mixed with Tris- $\mathrm{HCl}$ $(100 \mathrm{mM}, 150 \mu \mathrm{L})$ and hematin $(1.0 \mu \mathrm{M}, 10 \mu \mathrm{L})$ and shaken gently for $2.0 \mathrm{~min}$. After that, $10 \mu \mathrm{L}$ of the tested sample solutions $(0.46-333 \mu \mathrm{g} / \mathrm{mL})$ was added and incubated for $5.0 \mathrm{~min}$. Then, arachidonic acid $(100 \mu \mathrm{M}, 10 \mu \mathrm{L})$ and TMPD $(10 \mu \mathrm{M}, 10 \mu \mathrm{L})$ were added to the initiated the reaction, and finally, the reaction mixtures were terminated by the addition of $\mathrm{HCl}$ solution $(2.0 \mathrm{M}, 20 \mu \mathrm{L})$ after incubation for $5.0 \mathrm{~min}$. The optical values (OD) of the reaction mixtures were monitored at the wavelength of $590 \mathrm{~nm}$. The $\mathrm{IC}_{50}$ value and its dose-dependent curve of the SPRE sample were acquired based on the non-linear regression analysis (GraphPad, v5.01). The data were expressed as Mean \pm SD of three replicates.

\subsection{HPLC-UV/ESI-MS/MS Analysis of R. prinoides}

The HPLC-UV/ESI-MS/MS Analysis of R. prinoides was implemented by using the Termo Accela 600 HPLC system, which was connected with the TSQ Quantum Access MAX mass spectrometer (Termo Fisher Scientific, San Jose, CA, USA). A Waters SunFire ${ }^{\mathrm{TM}}$ RP-C18 column $(150 \mathrm{~mm} \times 4.6 \mathrm{~mm}$, $3.5 \mu \mathrm{m}$ ) was employed for the chromatographic separation. The $\mathrm{H}_{2} \mathrm{O}(\mathrm{A})$ and acetonitrile (B) were used as the mobile phases, and the elution gradient was set as follows: $0-2 \mathrm{~min}, 15 \% \mathrm{~B} ; 2-45 \mathrm{~min}, 14 \%-45 \%$ B; 45-55 min, 45\% - 60\% B; 55-60 min, 60\% - 15\% B. The injection volume was $10 \mu \mathrm{L}$, the flow rate was $0.5 \mathrm{~mL} / \mathrm{min}$, the column temperature was kept at $30^{\circ} \mathrm{C}$, and the on-line UV chromatograms were monitored at $360 \mathrm{~nm}$. The relative quantitative analysis was calculated by the proportion of the AUC 
of one component in the HPLC-UV chromatogram profile to the total AUC of all components. For the following ESI-MS/MS analysis, the MS/MS conditions were set the same as those of our previous study [23].

\subsection{Statistical Analysis}

All the statistical analysis was performed using the SPSS program (V 16.0). One-way ANOVA with the Tukey and LSD tests was employed to compare the significance between groups. All the values are present to be the Mean \pm SD (standard deviation, $n=3$ ), and the significant differences were considered at $p \leq 0.05$ and $p \leq 0.01$.

\section{Conclusions}

In the present study, the noteworthy antioxidant and anti-inflammatory activities of the polyphenols of R. prinoides from Mount Kenya were comprehensively evaluated for the first time. As a result, the polyphenol enriched extracts of CRE and SPRE displayed strong antioxidant activities by capturing the DPPH and $\mathrm{ABTS}^{+}$free radicals. Along with the higher contents of polyphenols and flavonoids, and the stronger antioxidant activities, the SPRE showed potential anti-inflammatory activities by reducing the NO production and the COX-2 activity. On the other hand, further HPLC-UV/ESI-MS/MS analysis of the polyphenol profile of $R$. prinoides revealed that flavonoids and their glycosides not only made up the major ingredients but were also potentially responsible for its strong antioxidant and anti-inflammatory activities. In conclusion, the present study comprehensively demonstrated that the high content of polyphenols in $R$. prinoides, along with noteworthy antioxidant and anti-inflammatory activities, confirmed that $R$. prinoides is a good natural source of polyphenols and flavonoids, and provided further scientific evidences for its use as folk medicine and with good potential for future healthcare practice.

Author Contributions: M.-Q.G. and G.-W.H. conceived of, designed, and supervised the study. G.-L.C., F.M.M., Y.-B.X., and F.D.S. performed the experiments, analyzed the data, and wrote the manuscript. All authors reviewed and approved the final manuscript.

Funding: This work was partly supported by the National Natural Science Foundation of China (Grant No. 81903791 to G.-L. Chen), and the Natural Science Foundation of Hubei Province (Grant No. 2019CFB254 to G.-L. Chen). The funders played no roles in the study design, data collection and analysis, and decision to publish.

Conflicts of Interest: The authors declare no conflict of interest. The funders had no role in the design of the study; in the collection, analyses, or interpretation of data; in the writing of the manuscript, or in the decision to publish the results.

\section{References}

1. Nagari, A.; Abebaw, A. Determination of selected essential and non-essential metals in the stems and leaves of Rhamnus prinoides (Gesho). Sci. Technol. Arts Res. J. 2013, 2, 20-26. [CrossRef]

2. Jelagat, K.P. In-Vivo Anti-Helminthic Activity of Rhamnus prinoides (Misizitwe) Extracts on Ascaris Lumbricoides; Univ. of Nairobi: Nairobi, Kenya, 2014.

3. Berhanu, A. Microbial profile of Tella and the role of gesho (Rhamnus prinoides) as bittering and antimicrobial agent in traditional Tella (beer) production. Int. Food Res. J. 2014, 21, 357-365.

4. Takele, F.; Dagninet, A.; Biazen, E.; Tigsit, G. Rhamnus prinoides in north west Ethiopia: Production, contribution and constraints. Recent Adv. Petrochem. Sci. 2018, 4, 555647-555652.

5. Gebre, A.; Chandravanshi, B.S. Levels of essential and non-essential metals in Rhamnus prinoides (gesho) cultivated in Ethiopia. Bull. Chem. Soc. Ethiop. 2012, 26, 329-342. [CrossRef]

6. Kiringe, J.W. A survey of traditional health remedies used by the Maasai of southern Kaijiado district, Kenya. Ethnobot. Res. Appl. 2006, 4, 61-73. [CrossRef]

7. Prozesky, E.A.; Meryer, J.J.; Louw, A.I. In vitro antiplasmodial activity and cytotoxicity of ethnobotanically selected south African plants. J. Ethnopharmacol. 2001, 76, 239-245. [CrossRef]

8. Njoroge, G.N.; Bussmann, R.W. Diversity and utilization of antimalarial ethnophytotherapeutic remedies among the Kikuyus (central Kenya). J. Ethnobiol. Ethnomed. 2006, 2, 8-14. [CrossRef] 
9. Muregi, F.W.; Chhabra, S.C.; Njagi, E.N.M.; Lang'at-Thoruwa, C.C.; Njue, W.M.; Orago, A.S.S.; Omar, S.A.; Ndiege, I.O. In vitro antiplasmodial activity of some plants used in Kisii, Kenya against malaria and their chloroquine potentiation effects. J. Ethnopharmacol. 2003, 84, 235-239. [CrossRef]

10. Muregi, F.W.; Ishih, A.; Suzuki, T.; Kino, H.; Amano, T.; Mkoji, G.M.; Miyase, T.; Terada, M. In vivo antimalarial activity of aqueous extracts from Kenyan medicinal plants and their chloroquine (CQ) potentiation effects against a blood-induced CQ-resistant rodent parasite in mice. Phytother. Res. 2007, 21, 337-343. [CrossRef]

11. Crowch, C.M.; Okello, E.J. Kinetics of acetylcholinesterase inhibitory activities by aqueous extracts of Acacia nilotica (L.) and Rhamnus prinoides (L'hér.). Afr. J. Pharm. Pharmacol. 2009, 3, 469-475.

12. Nindi, M.M.; Kgarebem, B.V.; Wolfender, J.L.; Abegaz, B.M. Electrospray liquid chromatography-mass spectrometry of the leaf extract of Rhamnus prinoides. Phytochem. Anal. 1999, 10, 69-75. [CrossRef]

13. Abegaz, B.M.; Peter, M.G. Emodin and emodinanthrone rhamnoside acetates from fruits of Rhamnus prinoides. Phytochemistry 1995, 39, 1411-1414. [CrossRef]

14. Abegaz, B.M.; Kebede, T. Geshoidin: A bitter principle of Rhamnus prinoides and other constituents of the leaves. Bull. Chem. Soc. Etiop. 1995, 9, 107-114.

15. Abegaz, B.; Ermias, D. Anthracene derivatives of Rhamnus prinoides. Bull. Chem. Soc. Etiop. 1988, 2, 15-20.

16. Alemu, H.; Abegaz, B.M.; Bezabih, M. Electrochemical behaviour and voltammetric determination of geshoidin and its spectrophotometric and antioxidant properties. Bull. Chem. Soc. Ethiop. 2007, 21, 189-204.

17. Ammar, R.B.; Bhouri, W.; Sghaier, M.B.; Boubaker, J.; Skandrani, I.; Neffati, A.; Bouhlel, I.; Kilani, S.; Mariotte, A.M.; Chekir-Ghedira, L.; et al. Antioxidant and free radical- scavenging properties of three flavonoids isolated from the leaves of Rhamnus alaternus L. (Rhamnaceae): A structure-activity relationship study. Food Chem. 2009, 116, 258-264. [CrossRef]

18. Bhouri, W.; Sghaier, M.B.; Kilani, S.; Bouhlel, I.; Dijoux-Franca, M.G.; Ghedira, K.; Ghedira, L.C. Evaluation of antioxidant and antigenotoxic activity of two flavonoids from Rhamnus alaternus L. (Rhamnaceae): Kaempferol 3-O- $\beta$-isorhamninoside and rhamnocitrin 3-O- $\beta$-isorhamninoside. Food Chem. Toxicol. 2011, 49, 1167-1173. [CrossRef]

19. Molla, Y.; Nedi, T.; Tadesse, G.; Alemayehu, H.; Shibeshi, W. Evaluation of the in vitro antibacterial activity of the solvent fractions of the leaves of Rhamnus prinoides L' herit (Rhamnaceae) against pathogenic bacteria. BMC Complement. Altern. Med. 2016, 16, 287. [CrossRef]

20. Tacherfiout, M.; Petrov, P.D.; Mattonai, M.; Ribechini, E.; Ribot, J.; Bonet, M.L.; Khettal, B. Antihyperlipidemic effect of a Rhamnus alaternus leaf extract in triton-induced hyperlipidemic rats and human Hep G2 cells. Biomed. Pharmacother. 2018, 101, 501-509. [CrossRef]

21. Lee, J.S.; Shukla, S.; Kim, J.A.; Kim, M. Anti-angiogenic effect of Nelumbo nucifera leaf extracts in human umbilical vein endothelial cells with antioxidant potential. PLoS ONE 2015, 10, e0118552. [CrossRef]

22. Zhu, M.Z.; Chen, G.L.; Wu, J.L.; Li, N.; Liu, Z.H.; Guo, M.Q. Recent development in mass spectrometry and its hyphenated techniques for the analysis of medicinal plants. Phytochem. Anal. 2018, 29, 365-374. [CrossRef] [PubMed]

23. Chen, G.L.; Li, X.; Saleri, F.D.; Guo, M.Q. Analysis of flavonoids in Rhamnus davurica and its antiproliferative activities. Molecules 2016, 21, 1275-1288. [CrossRef] [PubMed]

24. Liu, G.Y.; Zhuang, L.W.; Song, D.D.; Lu, C.L.; Xu, X. Isolation, purification, and identification of the main phenolic compounds from leaves of celery (Apium graveolens L. var. dulce Mill./Pers.). J. Sep. Sci. 2017, 40, 472-479. [CrossRef] [PubMed]

25. Boussahel, S.; Speciale, A.; Dahamna, S.; Amar, Y.; Bonaccorsi, I.; Cacciola, F.; Cimino, F.; Donato, P.; Ferlazzo, G.; Harzallah, D.; et al. Flavonoid profile, antioxidant and cytotoxic activity of different extracts from Algerian Rhamnus alaternus L. bark. Pharmacogn. Mag. 2015, 11, 102-109.

26. Benamar, H.; Rarivoson, E.; Tomassini, L.; Frezza, C.; Marouf, A.; Bennaceur, M.; Nicoletti, M. Phytochemical profiles, antioxidant and anti-acetylcholinesterasic activities of the leaf extracts of Rhamnus lycioides subsp. oleoides (L.) Jahand. \& Maire in different solvents. Nat. Prod. Res. 2019, 33, 1456-1462.

27. Kosalec, I.; Kremer, D.; Locatelli, M.; Epifano, F.; Genovese, S.; Carlucci, G.; Randic, M.; Zovko Koncic, M. Anthraquinone profile, antioxidant and antimicrobial activity of bark extracts of Rhamnus alaternus, R. Fallax, R. intermedia and R. pumila. Food Chem. 2013, 136, 335-341. [CrossRef]

28. Locatelli, M.; Epifano, F.; Genovese, S.; Carlucci, G.; Zovko Končić, M.; Kosalec, I.; Kremer, D. Anthraquinone profile, antioxidant and antimicrobial properties of bark extracts of Rhamnus catharticus and R. orbiculatus. Nat. Prod. Commun. 2011, 6, 1275-1280. [CrossRef] 
29. Garzon, G.A.; Narvaez-Cuenca, C.E.; Vincken, J.P.; Gruppen, H. Polyphenolic composition and antioxidant activity of acai (Euterpe oleracea mart.) from Colombia. Food Chem. 2017, 217, 364-372. [CrossRef]

30. Cho, H.; Yun, C.W.; Park, W.K.; Kong, J.Y.; Kim, K.S.; Park, Y.; Lee, S.; Kim, B.K. Modulation of the activity of pro-inflammatory enzymes, COX-2 and iNOS, by chrysin derivatives. Pharmacol. Res. 2004, 49, 37-43. [CrossRef]

31. Cao, H.; Yu, R.; Tao, Y.; Nikolic, D.; van Breemen, R.B. Measurement of cyclooxygenase inhibition using liquid chromatography-tandem mass spectrometry. J. Pharm. Biomed. Anal. 2011, 54, 230-235. [CrossRef]

32. Kim, J.H.; Kim, A.R.; Kim, H.S.; Kim, H.W.; Park, Y.H.; You, J.S.; Park, Y.M.; Her, E.; Kim, H.S.; Kim, Y.M.; et al. Rhamnus davurica leaf extract inhibits fyn activation by antigen in mast cells for anti-allergic activity. BMC Complement. Altern. Med. 2015, 15, 80. [CrossRef] [PubMed]

33. Wei, B.L.; Lu, C.M.; Tsao, L.T.; Wang, J.P.; Lin, C.N. In vitro anti-inflammatory effects of quercetin 3-O-methyl ether and other constituents from Rhamnus species. Planta Med. 2001, 67, 745-747. [CrossRef] [PubMed]

34. Chen, G.L.; Wu, J.L.; Li, N.; Guo, M.Q. Screening for anti-proliferative and anti-inflammatory components from Rhamnus davurica pall. using bio-affinity ultrafiltration with multiple drug targets. Anal. Bioanal. Chem. 2018, 6, 1-9.

35. Ruchado, P.; Vit, P.; Heard, T.A.; Tomas-Barberan, F.A.; Ferreres, F. Determination of interglycosidic linkages in O-glycosyl flavones by high-performance liquid chromatography/photodiode-array detection coupled to electrospray ionization ion trap mass spectrometry. Its application to Tetragonula carbonaria honey from Australia. Rapid Commun. Mass Spectrom. 2015, 29, 948-954.

36. Lai, J.P.; Lim, Y.H.; Su, J.; Shen, H.M.; Ong, C.N. Identification and characterization of major flavonoids and caffeoylquinic acids in three Compositae plants by LC/DAD-APCI/MS. J. Chromatogr. B 2007, 848, 215-225. [CrossRef] [PubMed]

37. Liu, T.; Zhu, M.Z.; Zhang, C.Y.; Guo, M.Q. Quantitative analysis and comparison of flavonoids in lotus plumules of four representative lotus cultivars. J. Spectrosc. 2017, 2017, 1-9. [CrossRef]

38. Zhu, M.Z.; Wu, W.; Jiao, L.L.; Yang, P.F.; Guo, M.Q. Analysis of flavonoids in lotus (Nelumbo nucifera) leaves and their antioxidant activity using macroporous resin chromatography coupled with LC-MS/MS and antioxidant biochemical assays. Molecules 2015, 20, 10553-10565. [CrossRef]

39. Deng, J.L.; Liu, R.; Lu, Q.; Hao, P.Y.; Xu, A.Q.; Zhang, J.L.; Tan, J. Biochemical properties, antibacterial and cellular antioxidant activities of buckwheat honey in comparison to manuka honey. Food Chem. 2018, 252, 243-249. [CrossRef]

40. Zou, Y.P.; Chang, S.K.; Gu, Y.; Qian, S.Y. Antioxidant activity and phenolic compositions of lentil (Lens culinaris var. Morton) extract and its fractions. J. Agric. Food Chem. 2011, 59, 2268-2276. [CrossRef]

41. Chen, G.L.; Fan, M.X.; Wu, J.L.; Li, N.; Guo, M.Q. Antioxidant and anti-inflammatory properties of flavonoids from lotus plumule. Food Chem. 2019, 277, 706-712. [CrossRef]

42. Huang, C.Q.; Li, W.; Zhang, Q.F.; Chen, L.H.; Chen, W.M.; Zhang, H.C.; Ni, Y.X. Anti-inflammatory activities of Guang-pheretima extract in lipopolysaccharide-stimulated raw 264.7 murine macrophages. BMC Complement. Altern. Med. 2018, 18, 46-56. [CrossRef] [PubMed]

(C) 2020 by the authors. Licensee MDPI, Basel, Switzerland. This article is an open access article distributed under the terms and conditions of the Creative Commons Attribution (CC BY) license (http://creativecommons.org/licenses/by/4.0/). 